\title{
Social Structure, Culture, and Crime: Assessing Kornhauser's Challenge to Criminology ${ }^{1}$
}

\author{
Ross L. Matsueda
}

Ruth Kornhauser's (1978) Social Sources of Delinquency has had a lasting influence on criminological theory and research. This influence consists of three contributions. First, Kornhauser (1978) developed a typology of criminological theories - using labels social disorganization, control, strain, and cultural deviance theories - that persists today. She distinguished perspectives by assumptions about social order, motivation, determinism, and level of explanation, as well as by implications for causal models of delinquency. Second, Kornhauser addressed fundamental sociological concepts, including social structure, culture, and social situations, and provided a critical evaluation of their use within different theoretical perspectives. Third, she helped foster a resurgence of interest in social control and social disorganization theories of crime (e.g., Gottfredson and Hirschi 1990; Hirschi 1969; Sampson and Laub 1993; Bursik and Webb 1982; Kubrin and Weitzer 2003; Sampson and Groves 1989), both indirectly via the influence of an early version of the manuscript that would become Social Sources (see Chapter 3 in this volume) on Hirschi's (1969) Causes of Delinquency, and directly via the influence of her book on the revitalization of social disorganization theories of crime.

Kornhauser's influence on the writings of Hirschi, Bursik, and Sampson was particularly significant and positive, as control and disorganization theories came to dominate the discipline, stimulating a large body of research that increased our understanding of conventional institutional control of crime and delinquency through community organization, family life, and school effects. 
At the same time, Kornhauser also had a negative impact on criminological theory. She provided a critique of what she labeled, "cultural deviance theories," into which she categorized Sutherland's (1947) theory of differential association. This critique drew criminological attention away from ideas that had dominated the field, including culture, subculture, conflict, and peer effects. This inattention paralleled a similar shift in the sociology of poverty during the 1970s and 1980s, in which the concept of culture became associated with the idea of a "culture of poverty." During the last decade, the concept of culture has re-emerged in sociology, with the resurgence of urban ethnographies and the reconceptualization of culture as frames, toolkits, symbolic boundaries, and cultural capital. Interest in peer effects has also regained favor with the development of social network data and models. A parallel development has lagged somewhat in criminology, which was once at the forefront of research on peers and subcultures. Indeed, some of the most prominent studies en inner-city culture and crime in the 1980s and 1990s were conducted by non-criminologists, such as urban ethnographers (e.g., Anderson 1999; Horowitz 1983; Katz 1988).

In this chapter, I review Kornhauser's (1978) major contributions to criminological theory and research, focusing on her typology of criminological theories. First, I discuss the intellectual influences that helped shape Kornhauser's approach to criminological theory, including Parsons's $(1937,1951)$ functionalist approach and Jaeger and Selznick's (1964) normative theory of culture. Second, I revisit her construction and critique of "cultural deviance theory," and speculate about what led her to misinterpret the writings of Sutherland and other members of the Chicago School of Sociology. Finally, I reconsider the issues of social structure and culture raised by Kornhauser and outline a strategy for remedying her errors and moving beyond her presentation to a research agenda for criminology.

\section{Kornhauser's Underlying Perspective}

Criminologists who assess Kornhauser's (1978) work rarely discuss her theoretical influences, with the exception of her alignment with social disorganization and social control perspectives. Writing in the early 1960s, Kornhauser was strongly influenced by structural functionalism generally and by the writings of Talcott Parsons (1951) specifically. Her conception of culture, in particular, is consistent with Kroeber and Parsons's (1958) normative theory of culture, and its elaboration by Jaeger and Selznick (1964). To understand Kornhauser's arguments - especially her conception of culture as core values - it is helpful to review Parsons's writings.

Parsons's $(1937,1951)$ work had two objectives: (1) attempt to offer a solution to the Hobbesian problem of order; and (2) attempt to specify a voluntaristic theory of action based on means-ends schemes that could resolve the neoclassical-institutional debate in economics (Camic 1987). His solution to the problem of order introduced the sociological concepts of normative regulation and ultimate social values into the means-ends chain, which, for Parsons, 
constitutes the unit act. Instead of being random, as is assumed by utilitarian models, Parsons hypothesized that people's egoistic goals would be shaped by stable, person-specific internalized values, pursued "for their own sake" (Camic 1989). When such values are shared by members of a specific culture, the means to attain them would be lawfully governed and enforced by members of that group through normative regulation. Such regulation would prevent force and fraud, and would be obeyed out of obligation and respect to one's culture (Parsons 1937: 389). As Camic (1989: 85) points out, Parsons's normative solution relies on three presuppositions: (1) common normative elements exist on a large scale; (2) these normative elements translate into both ends and normative regulation of means; and (3) actors uphold ends and regulations out of moral obligation. Each of these presuppositions has been questioned empirically by sociologists.

Empirical research finds that common normative elements fail to dominate both in modern societies, because of subcultural elements based on class or religion, and in traditional societies, because of barriers to communication of common norms (see Camic 1989). Research also suggests that abstract values fail to translate directly into specific normative rules because shared values tend to be too general, contradictory, and fluid to regulate force and fraud in everyday life, and, even if they could so translate, vary substantially by the cultural integration of institutional domains, such as legal, mass media, and moral (see Camic 1989). Finally, research finds that many societies attain relatively strong social order not from value consensus, but rather from political, economic, and organizational processes (e.g., Alexander 1983). Moreover, this negative empirical evidence reflects a theoretical weakness of Parsons's theory of action: The abstract solution to the problem of order is necessarily ahistorical - stated in terms of abstract concepts of values, which rules out the concrete historically specific context, including political-economic processes created by actors exercising agency.

In addressing the problem of order and specification of a voluntaristic theory of action, Parsons lays out his famous tripartite schema, consisting of three analytically distinct systems: the social system (individuals interacting within a situation, including an environment), the personality system (the primary agency of action processes oriented toward goal attainment), and the cultural system (complexes of symbolic meanings). The functional prerequisite of a cultural system is to mediate social systems and personality systems through processes of socialization.

This integration of a set of common value patterns with the internalized need disposition structure of the constituent personalities is the core phenomenon of the dynamics of social systems (Parsons 1951: 42). However, as Alexander (1990: 5) points out, Parsons made a consequential recommendation that reduced culture from complexes of symbolic meanings to institutionalized core values:

Functional analysis should be concerned with the institutionalization of culture, with how culture becomes part of the real structures of social systems. This focus on institutionalization, Parsons believed, would substantially narrow the cultural interest of 
sociologists; henceforth, they would focus on "values" rather than on symbol systems as such. Values are symbolic, abstract ways of talking about central institutional problems.

The result was the "first step toward a normative theory of culture" (Somers 1995: 118).

Jaeger and Selznick (1964: 656) follow Parsons (1951), and particularly, Kroeber and Parsons (1958), to develop more fully a normative theory of culture, defining culture as "values, ideas, and other symbolic-meaning systems." Jaeger and Selznick incorporate some elements of pragmatism-Mead's (1934) concept of the self and Dewey's (1958) concepts of esthetics and symbolic meaningbut they also depart from pragmatism. They embrace Freud for the concept of inadequate socialization to cultural values. ${ }^{2}$ Presaging Kornhauser (1978), they reject cultural relativity, positing that defective socialization to cultural values is the cause of deviance, and argue that:

Some students of society may continue to affirm that it is always content and never quality that is at stake in socialization. They will interpret delinquency, for example, as merely a different kind of behavior, aspiration, and belief resulting from differential association. On the other hand, there is an older and continuing tradition which distinguishes between "pathological" and other forms of deviance and interprets some kinds of socialization as not only different but faulty or incomplete (p. 657).

Deviance is important for Parsons because a basic functional prerequisite of social systems is to minimize disruptive behaviors and their motivations by integrating personalities (need dispositions) with normative cultural standards (value orientations). Such integration would result in a social system with institutionalized role expectations congruent with individual value orientations so that within situations, actors follow consensual norms and values. It follows that, when sub-systems are incongruent, strains arise - ego has not internalized the common value patterns necessary to suppress ego's need dispositions - which produces deviant behavior. This argument from Parsons may explain Kornhauser's initial enthusiasm for strain theory, as noted by Hirschi (1996: 251).

Like the work of Parsons, Kornhauser's monograph is sprinkled with discussions of the functions of social phenomena for a social system: stratification gives rise to functional differentiation; value consensus has a positive function for producing social order; and the cultural system consists of deep-seated consensual values that function to mediate personality and social systems. Her analysis of deviance uses Parsons's key concepts, including social structure, culture, integration, situation, and value orientation. ${ }^{3}$ In analyzing Sutherland (1947), for example, she uses the concepts of subculture, perfect socialization, and value orientation - concepts that do not appear in Sutherland's writing.

In applying these ideas and tools to the study of crime and deviance, Kornhauser (1978) stresses the importance of treating each concept as a variable, varying systematically across individuals, which would then help explain 
individual differences in deviant behavior. Consequently, deviance is explained by weak culture, weak social structure, and, in general, weak conventional controls over deviant impulses. Thus, Kornhauser is drawn to social control theories (e.g., Hirschi 1969; Matza 1964; Reiss 1951; Toby 1957).

\section{Typologies and Assumptions of Theories}

The principal strength of Kornhauser's book is organizing the leading criminological theories of the time into a three-fold typology of perspectives. She differentiates each perspective by its underlying assumptions about human nature, human motivation, definition of delinquency, and cultural variability, by their treatment of culture, social structure, and situation, and by their implications for competing causal models of delinquency. If done correctly, such a typology would have advanced the field considerably. Unfortunately, her execution ends up falling short.

Kornhauser first distinguishes between "cultural deviance" and "social disorganization" perspectives, and then further subdivides disorganization into "strain" and "control" variants. Under her category of cultural deviance theory, Kornhauser includes Sellin's (1938) culture conflict, Miller's (1958) lower-class culture, and Wolfgang and Ferracuti's (1967) subculture of violence-and treats Sutherland's (1947) theory of differential association as the "pure form." Under strain theory, she considers Merton's (1938) theory of social structure and anomie as the pure form. Finally, under control theory, she lists Thrasher's theory of the gang as the pure form, along with Hirschi's (1969) social control theory. Several important criminological theories do not fit into this typology; therefore, Kornhauser creates additional categories for "mixed" models, which combine contradictory assumptions of two or more of her model types: Shaw and McKay ([1942] 1969), she maintains, combine control and cultural deviance models, whereas Cohen (1955) and Cloward and Ohlin (1960) combine strain and cultural deviance models. Her primary contrast is between, on the one hand, social disorganization theories, which she argues attribute deviance to a lack of articulation of values within culture (control theory) or between culture and structure (strain theory) and, on the other hand, cultural deviance theories, which she argues attribute deviance to perfect socialization to subcultural norms.

Kornhauser (1978) then characterizes the three theoretical perspectives by key assumptions, treatment of structure and culture, and causal implications. Thus, she assumes that the constituent theories within each general category conform to her characterization of the category, while discounting differences among them. Consequently, to fit specific theories into her typology, she selectively emphasizes some elements of specific theories and ignores others. ${ }^{4}$ For example, in presenting Thrasher as a "pure control theorist," Kornhauser (1978) discounts many of his key arguments. Thrasher (1927) drew on the work of Park and Burgess on the role of socially disorganized areas within the city of Chicago as well as on 
W. I. Thomas's (1923) concept of the definition of the situation. He found that neighborhood disorganization tends to isolate boys from conventional cultural patterns and encourages them to develop behavioral patterns based on conventions and rules within their own social world. More established gangs make up a key dimension of this "moral region" and often induce others into delinquency. For Thrasher (1927: 265-267, 284), this is "education in the streets," which forms "tastes and habits, ambitions and ideals." Such learning is often elaborate, as "the gang is capable of deliberation, planning, and cooperation in a highly complex undertaking," and includes learning a code of conduct governing members of the gang, as well as learning to define situations as calling for criminal behavior: "The gang boy sees lawlessness everywhere, and in the absence of effective definitions to the contrary accepts it without criticism" (see Matsueda 2008). These findings helped form the basis of Shaw and McKay's ([1942] 1969) concept of cultural transmission and Sutherland's concept of differential association. Only by completely discounting this process of cultural transmission, the role of moral codes of the gang, and the importance of definitions of situations calling for crime is Kornhauser (1978) able to categorize Thrasher as a "pure" control theorist who sees gang delinquency as solely a result of weak community controls.

Shaw and McKay ([1942] 1969) are also misconstrued: Kornhauser (1978) treats their theory of social disorganization and cultural transmission as internally contradictory (Matsueda 2008). After analyzing numerous life histories of delinquents (e.g., Shaw 1930)—which revealed tutelage and common views of delinquency - and after analyzing quantitative research on juvenile court records - which revealed interlocking patterns of delinquency across age-Shaw and McKay ([1942] 1969) concluded that a tradition of delinquency on the streets within interstitial neighborhoods is passed down from one generation of gang boys to the next through a process they termed "cultural transmission." Having interpreted cultural transmission to be an example of cultural deviance theory, Kornhauser (1978) concludes that Shaw and McKay ([1942] 1969) have combined contradictory perspectives into an internally inconsistent theory of delinquency. She reassesses their evidence (published writings only) on cultural transmission and dismisses it without justification. Finding everything about cultural deviance theory distasteful, she seeks to extract a "pure control theory" from Shaw and McKay by retaining only social disorganization: Youth with weak controls "become delinquent with or without the influence of delinquent companions" (1978: 69).

In rejecting the causal role of delinquent moral codes, cultural transmission, prestige of group hierarchies, and informal group control, Kornhauser (1978) is forced to ignore or reinterpret the voluminous qualitative evidence of Thrasher and Shaw and McKay. Kornhauser (1978: 70) incorrectly concludes that Shaw and McKay's “own case-history data, and other data, do not provide convincing evidence of the existence of delinquent values." As I noted elsewhere (Matsueda 2008: 112): 
Kornhauser's arguments are strongest when they explain delinquency using Shaw and McKay's explanatory concepts [social disorganization] and weakest when she tried to explain away their theoretical mechanisms (cultural transmission) and the empirical findings on which they are based.

Kornhauser's (1978) enthusiasm for her extraction of a "pure control version of social disorganization theory" is consistent with her Parsonian framework. Rooted in ultimate values and value consensus, rather than subcultural cleavages in behavioral repertoires, tools, or practice, culture is narrowed to conventional culture, and the hypothesis is that strong common culture functions to reduce deviance. Moreover, social disorganization, produced by a disjuncture between social, cultural, and personality systems, is a pathological state producing deviance because egoistic impulses go unchecked. The concept of individual motivation, minimized by Parsons, who reduces motivation to normative ends or egoistic impulses subsumed in personality systems (Camic 1989), is also minimized by Kornhauser (1978), falling under the rubric of untamed desires and impulses.

By contrast, Sutherland (1947), with his theory of differential association, tried to specify a social psychological theory of criminal motivation. This brings us to Kornhauser's (1978) most memorable contribution: her construction, critique, and rejection of "cultural deviance theory."

\section{Critique of "Culture Deviance Theory"}

The most provocative feature of Kornhauser's (1978) monograph is her critique of cultural deviance theory. Referring to an earlier version of her manuscript, Travis Hirschi (1969: 12) called it a "truly devastating critique of theories of cultural deviance." Indeed, her conclusion that social disorganization theories, and control theory in particular, were conceptually and empirically superior to other theories of crime was, first and foremost, rooted in her critique of cultural deviance theory.

In 1988, in a special issue of Crime and Delinquency devoted to the memory of Donald R. Cressey, I was invited to contribute an article on the current state of differential association theory. ${ }^{5}$ A major thesis of the article was that Kornhauser (1978) had misinterpreted Sutherland's (1947) theory of differential association and, by forcing it into her conception of "cultural deviance theory," had created a caricature of differential association. ${ }^{6}$ Years later, Akers (1996) restated my thesis, arguing that "Sutherland was not a cultural deviance theorist." Here, I briefly reiterate how Kornhauser (1978) misinterpreted Sutherland, and speculate on why she created a straw man of his theory.

\section{Sutherland's Theory of Differential Association}

Sutherland's theory of differential association assumes that crime is ultimately rooted in group conflict or, to use his term, culture conflict. Unlike primitive 
undifferentiated societies, which are relatively harmonious, consensual, and free of crime, modern industrial societies are characterized by groups that often conflict over interests, beliefs, and definitions of appropriate behavior. Sutherland (1947) followed Wirth (1931) and Sellin (1938) in arguing that crime is ultimately rooted in group conflict over definitions of the legal code. Cressey (1960) termed this "normative conflict" to distinguish it from the special case of conflict between immigrant and indigenous cultures.

Sutherland specified differential association to explain the social psychological process of how normative conflict in society produces individual acts of crime. Following social psychologists such as W. I. Thomas, Sutherland posited that criminal behavior is learned in a process of communication and interaction within primary groups. Such learning includes learning the techniques or skills of crime, some of which - for example, confidence games - are very specialized, as well as favorable or unfavorable definitions of the legal code. Here, Sutherland (1947) is using Thomas's (1923: 42) concept of the definition of the situation:

Preliminary to any self-determined act of behavior there is always a stage of examination and deliberation which we may call the definition of the situation. And actually not only concrete acts are dependent on the definition of the situation, but gradually a whole life-policy and the personality of the individual himself follow from a series of such definitions.

A definition of the situation helps an actor organize and justify a line of action. The importance of the concept of the definition of the situation, as opposed to the objective features of the situation, is summarized by the famous dictum by Thomas and Thomas (1928): "If men define situations as real they are real in their consequences." A moral code - a set of rules or norms that may be codified in law-constitutes the generally accepted definitions of abstract situations, which at times comes into conflict with individual definitions of situations that govern his or her wishes.

In explaining crime, Sutherland (1947) narrowed these definitions of situations to definitions favorable and unfavorable to the legal code. Although he described such definitions mostly by example, he did state that they included the specific direction of motives, drives, rationalizations, and attitudes, either toward crime or toward conformity. The important point is that motives, impulses, drives, and the like are neither inherently criminal nor noncriminal. Rather, general needs, values, and impulses can be satisfied in both criminal and noncriminal ways, and the question for differential association is what explains the alternative chosen. The key proposition of differential association is that a person engages in crime when he or she has learned an excess of definitions favorable to crime over those unfavorable to crime (Sutherland 1947). Definitions, however, are not equal, and vary by modalities of frequency, intensity, duration, and priority. Therefore, after weighting each definition by each of the four modalities, summing favorable and unfavorable definitions, and then taking the ratio of the two, if the ratio exceeds 
unity, the person will engage in the crime, provided he or she has learned the requisite techniques and has the objective opportunity to commit crime.

The key concept, then, is the ratio of definitions favorable and unfavorable to crime, which organizes and justifies a line of action, either criminal or conventional, in a situation in which crime is a possibility. Such definitions are consistent with C. Wright Mills's (1940) concept of vocabularies of motive. To illustrate the concept, Sutherland used the well-known adage, "It is okay to steal a loaf of bread when you are starving," which illustrates a moral dilemma: Does one violate the law if the harm of refraining from crime (theft) results in a greater harm (starvation) $?^{7}$ In his study of embezzlement, Cressey ([1953] 1973) found that embezzlers were typically respected businessmen with self-images as trusted and honest people. Nevertheless, when confronted by an unshareable financial problem, they used verbalizations such as "I was only borrowing the money and intended to pay it back," and "The money was entrusted to me, therefore, I could do what I wanted with it," to maintain a favorable self-image, while absconding with the money. Cressey's finding, as well as Sutherland's example, illustrate an important point: Criminals often apply definitions favorable to crime to justify violation of laws that they otherwise believe in. According to these definitions favorable to crime, the law does not apply in this specific situation.

Sykes and Matza (1957) later generalized this principle to the concept of techniques of neutralization, in which delinquents neutralize the law to justify their delinquency within a given situation. Sutherland's example of stealing bread falls under the technique of neutralization, "appeal to higher loyalties, " while Cressey's definitions favorable to embezzlement fall under "denial of harm." More recent examples of definitions of the legal code include Anderson's (1999) concept of the code of the street, which calls for violence to maintain street credibility, and Sampson and Bartusch's (1998) concept of "legal cynicism." Each of these concepts refers to elements of culture that are applied by criminals to offset the legitimacy of the law that is supported by definitions unfavorable to law violation.

Sutherland (1947) specified differential social organization to explain how normative conflict in society translates into group rates of crime: The crime rate of a group or society is determined by the extent to which it is organized in favor of crime versus organized against crime. Sutherland did not specify the content of such social organizations, except by example. Thus, organization in favor of crime includes the structure and culture of a gang, the structure and functions of the Mafia, the social system of insider trading within and between firms, and the organization of fences, fixes, and professional criminals. Organization against crime includes the legal system, local community organization, and conventional institutions such as the family, education, and religion. Anderson's (1999) discussion of the code of the street as a social system operating on the streets of inner-city neighborhoods is an example of organization in favor of crime (in this case, violence), which competes with the social organization of "decent" families. Of course, organizations are complex and typically contain elements of 
both organization against crime and in favor of crime. Mortgage lenders guilty of illicit predatory loans also provide entirely legitimate loans; the Mafia engages in predatory violence while adhering to a moral code governing family; pawn brokers sell legitimate as well as stolen goods.

Building on a little-known chapter by Sutherland's ([1943] 1973) on wartime crime, I elsewhere tried to revitalize the concept of differential social organization (Matsueda 2006a). There, I argued that when viewed dynamically, the concept of differential social organization becomes a theory of collective action, in which actors seek to mobilize in favor of crime or against crime. Such collective action is a function of a group's ability to mobilize resources, which in turn is a function of material resources and access to those resources through social network ties (social capital). Collective action toward or against crime is also a function of collective action frames and of their alignment with other frames held by constituents. Such frames, which consist of rhetorical devices, emotional pleas, and rational arguments, are ways of defining a situation as calling for collective action (see Goffman 1974; Snow, Rochford, Worden, and Benford 1986). When applied to collective illegal action, such frames correspond to definitions favorable to crime.

The resulting theory of differential social organization has proved fruitful in examining social control in two distinct social contexts. Hagan and RymondRichmond (2009) show how organization in favor of genocide-including building a coalition between the Sudanese government and Arab Janjaweed, mobilizing resources to incite collective acts of violence against black Africans, and using racial epithets to dehumanize the opposition and justify atrocities - fosters collective acts of genocide. Building on the social capital aspect of differential social organization, Sampson and Graif (2009) cluster Chicago communities by neighborhood organizational dimensions, and find that disadvantage is negatively associated with organizational involvement and collective efficacy, and residential stability is positively associated with conduct norms, organizational involvement, and leadership-based capital.

\section{Kornhauser's Construction of Cultural Deviance Theory}

Kornhauser (1978) carefully constructs "cultural deviance theory," arguing that Sutherland's theory of differential association is its "purest" case. She claims that Sutherland subscribed to a number of unstated underlying assumptions that undergird "cultural deviance theory" (see Matsueda 1988). First, there is no inherent human nature; humans are completely plastic at birth. Second, criminal laws reflect conflict among groups, and consequently there is no consensus in society. Paradoxically, social order is only possible with perfect consensus, and therefore society devolves into a war of subcultures, which vary only in content and not in strength. Culture, then, is present everywhere, and therefore is not a variable. Third, subcultures perfectly reflect structural differentiation, 
and therefore structure is indistinguishable from culture, and both are constants, present everywhere, and consequently, nowhere.

When the first two assumptions - no inherent human nature, and subcultures fail to vary in strength — are combined, a fourth assumption follows: socialization is always perfect, varying only by the particular subculture socializing its members. relative: heinous acts of murder, assault, and rape can be prescribed in some societies and subcultures within society. ance, only deviant cultures and subcultures. Hence, "cultural deviance theory."

\section{Kornhauser's Critique of Sutherland}

Kornhauser forces Sutherland's differential association theory to fit her conception of cultural deviance theory, and then dismisses both. As a consequence, in the words of her friend, Howard S. Becker, she made "Sutherland sound like some kind of a nut"' (Kornhauser 1984: vii). She begins by arguing that Sutherland's theory has no variables, only constants: Culture is a constant, differing only in content and not strength; social organization is a constant, always perfectly supporting culture; behavior is a constant, governed solely by perfect conformity to values and norms; situations are a constant, operating solely to give rise to definitions (Kornhauser 1978: 190). ${ }^{8}$ Furthermore, she argues that Sutherland ends up treating these concepts as identical: "Since behavior is always normative, and norms derive from cultural values, behavior and culture are the same thing" (p. 190). Moreover, she argues that social organization and culture are the same thing because differential social organization is equivalent to ratios of definitions of the legal code in different groups. Since situations are relevant to crime only as they are defined, and definitions are part of culture, situations and culture are the same. Culture is all.

Each of these arguments misrepresents Sutherland's writings. Sutherland (1947) did not write extensively about the problem of order, but his scattered treatments provide a view at odds with that of Parsons and Kornhauser. In discussing common laws, he notes that they likely developed through a crystallization of mores, while in discussing statutory law, he describes a process of normative conflict in which competing interest groups seek to mobilize the law in their favor (Matsueda 1988). Thus, it appears that, for Sutherland, crime is not completely relative, but varies over time and across societies, and social control is achieved in part by the coercive power of the state (Hobbes's Leviathan) and in part by consensus (Parsons's normative solution) (Matsueda 1988). ${ }^{9}$ Recognizing the diversity of culture in modern industrial societies, Sutherland narrows his explanatory concept of crime to definitions of the legal code. Such definitions vary from abstract principles, such as "always obey the law," to specific codes tied to groups, such as "never rat on a fellow criminal," and vary in content as well as strength (which Sutherland tries to highlight with his "modalities"). 
As noted above, Kornhauser, following Parsons, has no place for motivation as an important explanatory concept. For Kornhauser, motivation is neither problematic nor complex, having been reduced to egoistic impulses in need of control. Culture consists not of tools, skills, or motivations for or against crime, but rather a unidimensional concept of conventional core values. Therefore, Kornhauser reinterprets Sutherland's concept of definitions of the legal code to conform to her Parsonian definition of culture, as deep core values that supply designs for living in an organized society, and provide a normative solution to the Hobbesian problem of order. She then argues that Sutherland's subcultures contain values that require criminality - presumably touting crime as a lofty goal - and result in perfect socialization of members. ${ }^{10}$ In fact, in presenting his theory, Sutherland does not use the concepts of subcultures or values. Definitions of the legal code are indeed elements of culture that organize and justify a line of action, legal or criminal, but do not refer solely to core social values that are embedded within distinct subcultures. Moreover, such definitions are not the result of aleatory processes, as Kornhauser maintains, but are patterned by communication networks, which are structured by broader social organization, including the organization of families, peer groups, neighborhoods, communities, and nation-states (Matsueda 1988).

Differential social organization, which describes the organization of groups, affects rates of crime by influencing the distribution of definitions of the legal code within and between groups. That does not mean that social organization and culture are identical or that structural differentiation inevitably is mirrored perfectly by subcultural formation, which perfectly socializes its members. Here Sutherland is linking his group-level explanation with his social psychological explanation: The process of learning delinquency was his hypothesized explanation of the relationship between social structure and criminal behavior. Kornhauser (1978), however, is conflating levels of explanation and the distinction between a causal mechanism and a mathematical identity.

Moreover, Sutherland did not argue that all cultures and subcultures are equally binding on the behavior of individuals, but instead explicitly posited variation in the relative strength of organization in favor of crime versus organization against crime. He observed that, when crime rates increase, social groups typically respond by consciously increasing organization against crime-mobilizing politicians to speak out against crime, increasing funding for law enforcement, and using the media to alert citizens to the growing crime problem. Similarly, crime is not the result of perfect socialization to subcultural values, but rather is the result of learning definitions favorable to crime, which organize and justify a criminal line of action and which offset definitions unfavorable to crime (Matsueda 1988).

By using the concept of the definition of the situation, Sutherland did not equate situations with behavior and culture; rather, she argued that it is not merely the objective situation that is important, but one's subjective perception of the 
situation. Indeed, Sutherland ([1944] 1973) was aware of the importance of the situation, and admitted that his theory needed to incorporate two situational concepts: the objective opportunity for crime and the presence of alternative lines of action.

Finally, many of Kornhauser's criticisms of Sutherland derive from her structural functionalist Parsonian roots. Her substitution of consensual cultural values for Sutherland's concept of definitions of law violation derives from Parsons's preoccupation with Hobbes's problem of order, which he solved using the normative solution of value consensus. At times, she dismisses the possibility that culture can be transmitted intergenerationally, as Sutherland maintains, because only the elements of personality systems - a Parsonian concept — can be transmitted in such a way. Thus, within Parsons's social action framework, need dispositions derive from the personality system, normative values derive from the cultural system, and each is mediated by role expectations derived from the social system. Consequently, there is no natural place for the centrality of W. I. Thomas's concept of the definition of the situation.

Therefore, I surmise that Kornhauser (1978) followed this logical sequence: Definitions of situations are elements of culture; culture consists of deep core values; therefore, definitions of law violation are deep cultural values derived from powerful subcultures that compete on an equal basis with conventional culture. Rather than neutralizing the law in only certain situations, such values prescribe, extol, and glorify crime as an ideal design for living in all situations. Similarly, within Parsons's framework, which seeks a non-utilitarian solution to the problem of order and thereby emphasizes the functions of subsystems contributing to the stability of the social system, the pragmatist model based on social process has no natural place. For this reason, I suspect, Kornhauser (1978) had difficulty appreciating the dynamic process of differential social organization, and reduced the theory to a ubiquitous equivalence of culture and structure.

\section{Some Legitimate Shortcomings of Sutherland's Theory of Differential Association}

This is not to say that Sutherland's theory had no shortcomings, or that Kornhauser (1978) did not identify a few legitimate weaknesses in the theory. Differential association can be criticized on a number of grounds, most of which are errors of omission, rather than commission (for a classic discussion, see Cressey 1960). First, Sutherland specified the concept of definitions of the legal code very abstractly. He did not identify their elements, explain how they operated in situations, or provide a comprehensive inventory of their content for a given society or group. As noted above, others, such as Cressey ([1953] 1973) and Sykes and Matza (1957), specified the content of such definitions when applied to specific forms of crime and delinquency. 
Second, Sutherland did not provide a theory of cognition or a theory of the criminal situation. His hypothesis that crime results when the ratio of definitions favorable and unfavorable to crime exceeds unity is clearly oversimplified. How are definitions of crime applied within a given situation to produce crime? What accounts for the meanings embedded within such definitions? How are alternatives ruled out? A theory of social cognition and decision making would be necessary to show how such definitions are applied within a situation, as Short and Strodtbeck (1965) showed for group processes and gang delinquency. Perhaps the inclusion of concepts from American Pragmatism, including Dewey and Mead, and recent advances in dual processing in cognitive psychology would not merely fill this gap, but result in a substantially different explanation. ${ }^{11}$

Third, like many social scientists of his day, Sutherland ([1942] 1973) was committed to determinism and the use of analytic induction to develop and test deterministic hypotheses. This ruled out the possibility of agency and the use of probabilistic models, a criticism Kornhauser (1978) correctly makes. Thus, although knowledgeable of the writings of George Herbert Mead (e.g., Sutherland 1926), Sutherland departed from Mead's emphasis on agency in the construction of social meanings within an interaction and took a deterministic view of behavioral explanation. Analytic induction, in my opinion, is useful for generating hypotheses inductively from qualitative data, but less effective in testing hypotheses deductively, given the stochastic nature of human behavior and the presence of measurement error in social science indicators (e.g., Lieberson 1991).

Fourth, Sutherland did not identify the specific content of differential social organization, except by illustration, nor did he develop a theory of social structure. Although Sutherland did not assume that structure and culture were identical, as Kornhauser claims, he did fail to formally specify a theory of structure. To be fair, Sutherland's (1947) goal was to develop not a theory of structure or social organization, but rather a social psychological theory of individual criminal behavior. Nevertheless, his explanation is incomplete without a theory of social structure. Over the years, scholars have attempted to specify a theory of structure compatible with Sutherland's social psychology, drawing from Merton's (1938) theory of social structure and anomie (e.g., Cohen 1955; Cloward and Ohlin 1960), or the structure of social ties (e.g., Matsueda 2006a).

Unfortunately, by dismissing Sutherland's ideas based on Kornhauser's criticisms, many contemporary criminologists have been cut off from an important criminological tradition: the social psychology of the Chicago School, including Dewey, Mead, Thomas, and others. As a consequence, criminologists and sociologists have recently reinvented the wheel with concepts such as belief in morality, code of the street, and legal cynicism. Moreover, criminologists have failed to build on the notion of culture as rooted in social interaction (for an exception, see Sampson and Bean 2006). 


\section{Kornhauser's Legacy}

Despite my misgivings about Kornhauser's treatment of "cultural deviance theory," I wish to underscore the importance of her work for stimulating a resurgence of interest in social disorganization theory and, along with the work of Travis Hirschi (1969), social control theory. At the time, the concept of social disorganization had fallen out of favor in sociology, being viewed as antiquated, and criticized for being politically conservative. The classic critique came from C. Wright Mills (1943: 180), who equated social disorganization theorists with social pathologists. Mills argued that these "social pathologists" constituted a small homogenous politically conservative group that idealized "Protestant ideals in the small towns of America," and judged departures from those ideals as the result of under-socialization, maladaptation, and social pathology.

Despite such criticism, community studies of social disorganization were revived in the early 1980s. In a classic paper, Bursik and Webb (1982) tied social disorganization theory to the systemic approach to urban ecology and, using previously unanalyzed data from Shaw and McKay, found support for disorganization theory (see also Heitgard and Bursik 1987). Finding that the spatial distribution of delinquency rates did not remain completely stable in the years since Shaw and McKay's analyses, they argued for considering the role of local community politics in zoning and other residential patterns (see also Sampson 2012) - a conclusion that Mills (1943) would have appreciated. Sampson and Groves (1989) also found support for social disorganization theory, and identified informal social control of youth as a key intervening mechanism between community structure (representing social disorganization) and rates of criminal victimization. Sampson (2012) and his colleagues extended the social disorganization hypothesis by integrating concepts from social capital theory in their wellknown theory of collective efficacy (e.g., Sampson, Morenoff, and Earls 1999).

The major negative consequence of Kornhauser's (1978) work is that it contributed to criminology's inattention to the concept of culture and subculture. This neglect corresponded to a broader lack of attention to inner-city problems and the role of culture. In The Truly Disadvantaged, William Julius Wilson (1987) famously argued that, during the 1970s and 1980s, liberal social scientists had ignored the growing problems of the urban underclass for fear of being accused of "blaming the victim." Research on poverty in the 1960s had emphasized a "tangle of pathology" (Moynihan 1965) and a "culture of poverty," in which cultural values, attitudes, and beliefs conducive to poverty persist across generations even in the face of changing social structure (e.g., Lewis 1966). Wilson (1987) responded by highlighting the growing problems of the inner-city and developing, with his underclass thesis, a structural theory locating the genesis of the underclass not in a culture of poverty, but rather in broad historical, economic, and social transformations. At the same time, criminological interest turned away from the study of subcultures, which had dominated much of the 
scene in the 1950s and 1960s, to research on the structural sources of community disorganization and weak individual social controls. Indeed, studies of crime and violence using the concepts of culture and subculture came not from criminology, but from urban ethnography (e.g., Anderson 1999; Bourgois 2003; Horowitz 1983; Jankowski 1991). In particular, Horowitz's (1983) description of culture, honor, and identity within a Chicano community and Anderson's (1999) portrayal of the code of the street, street credibility, and "decent" versus "street" families were consistent with the general framework initiated by Sutherland (1947) as well as by Thrasher (1927), Shaw and McKay ([1942] 1969), and Cloward and Ohlin (1960), among others.

\section{Structure and Culture in Criminology}

What role should culture play in criminological theory? In this section, I review recent advances in cultural sociology and argue that a fruitful direction for criminological theory and research would integrate culture and social structure into multilevel models of purposive criminal action. This discussion extends Sampson and Bean's (2006) discussion of structure and culture in criminology by building on the ideas of American Pragmatism - which underlies much of the Chicago School of Social Psychology - and by considering culture as both means and ends, as intertwined with structure, and as forged from the concept of the definition of the situation.

Sociology, as well as other social sciences, has witnessed a resurgence of interest in the role of culture as part of an explanatory framework (see Lamont and Small 2008; Small, Harding, and Lamont 2010). ${ }^{12}$ Wilson (2010) himself has recently argued for including both social structure and culture in explaining inner-city poverty. Earlier, Sampson and Wilson (1995) articulated a theory of race and crime that emphasizes the role of social disorganization producing social isolation, which in turn attenuates conventional cultural values. This notion of culture, however, remained within Kornhauser's functionalist definition of culture as values. Given its rich tradition of subcultural theory and research, criminology would do well to return to considerations of culture, but without reverting to Parsons's definition of culture as immutable core values or Lewis's (1966) definition of culture as ultimate "designs for living." As noted above, when such myopic definitions of culture and subculture are applied to criminological theories, they result in theoretical caricatures such as Kornhauser's (1978) cultural deviance model. Similarly, when a definition of culture as core values and designs for living is applied to urban poverty, the result is a culture of poverty explanation (e.g., Lewis 1966).

Swidler (1986) illustrates this point by contrasting two cultural explanations of poverty — Lewis's (1966) culture of poverty thesis and Hannerz's (1969) theory of cultural repertoires. Whereas a culture of poverty explanation emphasizes the devaluation of upward mobility, hard work, and delayed gratification, and the valuation of welfare dependency, the cultural repertoires hypothesis emphasizes 
adaptation to circumstances using available cultural repertoires to organize a viable line of conduct. Thus, an inner-city impoverished male may give little thought to achieving success through higher education and white-collar occupations because he lacks the cultural repertoire - the social skills, cultural meanings, and accepted styles to negotiate the complexities of conventional institutions (see Lareau 2002). That would require substantial "cultural re-tooling" (Swidler 1986: 277). Instead, he may pursue status within his street group, given his knowledge of the code of the street, including "I got your back," "never back down," and "I'm a badass" (Anderson 1999).

\section{Varieties in the Concept of Culture: Repertoires, Toolkits, and Frames}

Before discussing the relationship between culture and social structure, it is helpful to clarify how recent social theorists define culture. Lamont and Small (2008) provided a concise summary of contemporary definitions of culture as repertoires, frames, symbolic boundaries, narratives, institutions, and cultural capital (see also Small et al. 2010). Consider the first two of these definitions: cultural repertoires and frames. Culture as repertoires consists less of ultimate values and more of realistic behavioral repertoires, social skills, habits, and styles - a toolkit - that individuals can use to construct strategies of action (Swidler 1986). Here, actors exercise agency in selecting from their available toolkits, specific strategies of purposive action. Such toolkits are distributed unevenly across the social structure; moreover, individuals may "invest" in culture by seeking to acquire skills, habits, and styles intentionally to facilitate attainment of objectives. Note the parallel with Sutherland's (1947) concept of the skills and techniques of committing crime - some of which are social skills, as in the case of professional theft — and the behavior patterns, which can be for or against criminal behavior.

Culture as frames elaborates the concept of a definition of a situation. Developed originally by Gregory Bateson (1972), frames were defined by Goffman (1974: 10-11) in terms of definitions of situations:

I assume that definitions of a situation are built up in accordance with principles of organization which govern events - at least social ones - and our subjective involvement in them: frame is the word I use to refer to each of these basic elements as I am able to identify. That is my definition of frame.

Goffman (1974) uses frame analysis to examine how actors come to understand "what is going on" in everyday face-to-face interactions. Although rooted in the concept of definitions of situations, Goffman departs from Thomas's dictum of definitions of situations being real in their consequences. Instead, he follows the phenomenological position of Schutz ([1932] 1967), bracketing the relationship between objective and subjective reality, and using the concept of frame as symbolic interactionists use the concept of "awareness contexts" (Glaser 
and Strauss 1964). Goffman's (1974) frame analysis, then, is less an analysis of what explains behavior - or the direction that interaction takes - but rather, as in ethnomethodology, an analysis of how interactants do what they do, including reaching consensus and understanding.

In contrast, recent applications of the concept of cultural frames use it to help explain collective action and individual behavior. ${ }^{13}$ For example, Snow et al. (1986) argue that frame alignment - the process of linking interpretive frameworks of social movement organizations with that of individual constituent - is key to mobilization. Small (2002) found that civic participation in a neighborhood declined because new cohorts of local residents no longer used a neighborhood frame that included the neighborhood's history of political and social involvement, an emphasis on the relatively positive features of the community, and the use of phrases like "community" and "project" to describe the neighborhood. When used as explanatory concepts, frames parallel Sutherland's concept of definitions of the legal code: Pro-crime frames are ways of making sense of a criminal situation as one in which criminal behavior is reasonable, justified, or inevitable (e.g., due to lack of agency), and anti-criminal frames are those making sense of an identical situation as one in which criminal behavior is unjustified, unreasonable, and controllable.

\section{Culture as Objectives versus Strategies}

The above example about culture of poverty explanations distinguishes two key aspects of culture: valued goals or ends of purposive action (achieving social status), and available means (cultural repertoires) for attaining those goals (through education and corporate training or tutelage on the streets). Note the parallel here with Merton's (1938) innovators, who, because of their location in lower rungs of the social structure, lack the legitimate means to attain conventional success and, therefore, innovate alternate ways of attaining status in illegitimate ways. Swidler's concept of cultural toolkits emphasizes the cultural means for attaining an objective and deemphasizes the objective itself, taking it as a given. But objectives and goals are a crucial portion of culture, and a thorough treatment of culture must include both goals and means. This is the theoretical strategy taken by Parsons, who conceived of all behavior as consisting of means-ends chains within unit acts - a strategy rife with problems, as pointed out by critics (e.g., Warner 1978).

How can objectives and goals be included into a concept of culture while avoiding the problems with Parsons's - and Kornhauser's — treatment? Parsons's means-ends schema treats means and ends as normatively regulated abstractions, and it allows one person's means to be another's ends, but always treats ends as exogenously determined. This model, as well as Merton's theory of social structure and anomie, has been criticized for using teleology-behavior is explained by fixed end states rather than antecedent states - which runs counter to the usual 
understanding of scientific causal explanations (e.g., Coleman 1990). John Dewey (1958) argued persuasively that means-ends explanations are unrealistic because typically actors have only a vague or diffuse goal, which is subject to change in interaction. Dewey coined the term "ends-in-view" to emphasize that ends are not externally fixed, but rather are shaped by interaction. Thus, the consideration of means may shape ends-in-view, and vice versa. Hans Joas (1996) built on Dewey's argument to specify a non-teleological approach to social action in which the situation is partly constitutive of action, perceptions of reality is in terms of judgments about the appropriateness of various actions, goals, objectives, and plans are necessarily vague and always subject to refinement and change. ${ }^{14}$ Thus, individuals enter a situation with habits and diffuse goals, and then, contingent on the situation, they reflectively consider alternatives for achieving a goal, which itself is shaped by the consideration of such alternatives. The emergent properties that arise from the reciprocal shaping of alternatives and objectives through reflection in interaction constitute agency (e.g., Emirbayer and Mische 1998; Matsueda 2006b).

Applied to the earlier example of a member of the urban underclass, the lack of the cultural tools necessary to excel within the educational system and the labor market may lead an individual to construct or create alternative goals. Having the cultural tools - street smarts, physical prowess, and toughness - may suggest the possibility of gaining status on the street, thereby altering perceptions of the streets from a dangerous setting to an arena rich in possibilities for status and respect. In the example of social movements, an anti-abortion organization may fashion a frame that resonates with fundamentalist Christians, thereby altering the goals of the organization to include religious ideology. In each of these examples, the emergence and use of culture as ends-in-view within social interaction creates identities of members of groups, as well as symbolic boundaries between in-group and out-group (see Lamont and Small 2008).

The approach advocated here is consistent with American Pragmatism, and the writings of Dewey (1958) and George Herbert Mead (1934). It would emphasize social process - as opposed to the stable structural functionalist model of Parsons - in which social behavior and interaction is ongoing, taking different directions based on the biographical histories of interactants and emergent properties arising from interactions in situations. Culture, then, is "intersubjective, not personal" (Sampson and Bean 2006). Here, attitudes and motives are "pivots for the redirection of behavior," arising within the interaction, rather than imposed externally (e.g., Dewey 1922). Motives, expressed through language, are inherently abstract and become historically concrete when actors interpret and apply them to social action (e.g., Mills 1940). Such vocabularies of motive have a history — one that can be identified by tracing their application and transmission across individuals and groups. Thus, in contrast to Parsons's ahistorical conception, culture is a historical phenomenon. Furthermore, vocabularies of motive, justifying crime (noncrime) are linked to a self or identity as a criminal 
(noncriminal). When action is interrupted, actors use vocabularies of motive in an imaginative rehearsal to try out alternative lines of action in advance (Dewey 1922). This is the process of cognition, a process ignored by Kornhauser and Parsons (see Warner 1978). In criminology, such a perspective has been used to explain the mechanisms by which life-course transitions explain criminal desistance. Giordano, Cernkovich, and Rudolph (2002) use the concept of "hooks for change" to characterize how life-course transitions, such as marriage, produce cognitive transformations in self and identity, which in turn help offenders exercise agency in desisting from crime.

\section{Social Structure and Culture}

Where is social structure in this formulation? Sampson and Bean (2006) identify three distinct treatments of structure and culture: (1) Structure explains behavior and culture is epiphenomenal and impotent, as argued by Kornhauser (1978). (2) Culture is an adaptation to structure - a causal mechanism linking structure to behavior. (3) Culture adapts to structure but can take on a life of its own, persisting - even in the face of changing structure - as a causal force. One can probably find empirical examples in which each of these positions appears valid. In some situations - such as when social structure changes dramatically, as in a financial crisis or the demise of a socialist state - social structure dominates as cultural habits fail to suffice and individuals struggle to adapt to changing circumstances. More commonly, culture typically adapts to social structure, as in Anderson's (1999) analysis of the code of the street, and would likely change in the face of changing structure. Finally, at times, culture persists in affecting behavior even after the social structure that gave rise to the cultural practice, disappears - as in ritualistic practices discussed by Merton (1968).

It is important to treat social structure as analytically distinct from culture, although the two are inextricably bound in reality. We can define social structure approximately as stable social relationships that provide access to resources. Thus, capitalist-worker, offender-victim, friendships, and familial relations all define social relationships and constitute structure. In criminology, important structures have been identified for explaining the distribution of criminal behavior. For example, the spatial structure of residential location at the neighborhood and community levels is crucial for understanding the spatial distribution of violence and other predatory crimes. Indeed, Sampson (2012) found that residential moves were largely horizontal, from one (dis)advantaged neighborhood to another. The organizational structure of the Mafia-with a boss at the top, soldiers on the bottom, and lieutenants, buffers, and enforcers in between-helps explain why it was so difficult to combat organized crime before passage of RICO laws (Cressey 1969). The organizational structure of industries and firms helps explain the opportunities and pressures for corporate crime. Firms in competitive industries and middle management within firms experience great competitive 
pressure to deviate (e.g., Clinard and Yeager 1980; Simpson 2002). Similarly, the relatively historically stable political-economic conflict between black Africans and Arabs over resources (arable land, horses, cattle, and water) in Sudan produces the structural incentives for conflict and genocide in Darfur (Hagan and Rymond-Richmond 2009).

Although structure and culture are reciprocally related, because structure is more stable, it is relatively more exogenous than culture. Elements of cultureframes, repertoires, and toolkits - provide ways of responding to the interests and opportunities deriving from structural position. For example, residential segregation by race and class produces cleavages in social ties, civic participation, and local organization, which in turn foster a culture of collective efficacy in affluent neighborhoods versus a culture of street violence in disadvantaged neighborhoods - dynamic elements of what can be termed differential neighborhood organization (Matsueda 2013). Such organization is related to identities of residents as "decent" versus "street" (Anderson 1999). Moreover, both collective efficacy and street violence act reciprocally to reproduce social structure. The organizational structure of the Mafia gives rise to a Mafia code - a set of beliefs and norms with clear sanctions carried out by an enforcer - to maintain social order within the organization (Cressey 1969). The structural pressures to succeed exerted on middle management within firms, and on firms in competitive industries, provide incentives for corporate actors to search for novel ways of bending rules, evading regulatory agencies, andincreasing efficiencies, and, importantly, identifying vocabularies of motive that justify such actions while maintaining a noncriminal identity. Hagan and Rymond-Richmond (2009) show that structural conflict over resources in Darfur provided incentives for nomadic Arabs to annihilate black Africans, using a racist collective action frame to dehumanize black Africans, incite an emotional frenzy during conflicts, and justify atrocities that would otherwise be unthinkable.

These threads of a treatment of culture and structure, of course, do not resolve the difficult but crucial issues about culture and structure raised by Kornhauser (1978). They do, however, suggest ways of framing the problem that depart from Parsons's functionalism and embrace ideas of pragmatism, which are more compatible with contemporary developments in social theory (e.g., Gross 2009; Joas 1993). Research and theory in criminology is needed to build on these ideas and extend concepts such as Giordano et al.'s (2002) notions of hooks for change and cognitive transformation, Sampson's (2012) concept of collective efficacy, Wilcox, Land, and Hunt's (2003) and Wikström, Oberwittler, Treiber, and Hardie's (2013) analyses of situations of crime, and Laub and Sampson's (2003) notion of agency over the life course.

\section{Conclusion}

Ruth Kornhauser (1978) has had a substantial effect on criminological research and theory. Positively, she helped stimulate the revitalization of social control 
theories of delinquency and social disorganization theories of crime rates across urban neighborhoods. Arguably the most productive research in criminology has developed in this framework, including life-course criminology and collective efficacy theory. Negatively, Kornhauser's (1978) adherence to Parsons's (1937, 1951) functionalist framework led her astray in creating cultural deviance theory, a caricature of the cultural theories of Sutherland, Sellin, Shaw and McKay, and others. This had the unfortunate consequence of leading many criminologists working within the control and disorganization frameworks to discount or ignore completely the concept of culture and the difficult problem of specifying how culture and social structure affect crime. The recent resurgence of interest in cultural sociology, and in particular the specification of (sub)culture in studies of urban poverty, has made culture relevant for criminology again. Because crime is by definition antisocial behavior implicating the possibility of subcultures, criminology is in an advantageous position to make a unique and significant contribution to the study of culture. Does it make sense to use the concept of subculture in explaining crime? Under what conditions do new (sub)cultures develop and old ones die out? How fluid is culture and subculture?

\section{Notes}

1. Revised version of a paper presented at the Annual Meetings of the American Society of Criminology, Chicago, IL, 2012. During the preparation of this chapter, the author was supported by a grant from the National Science Foundation (SES-0966662) and the Blumstein-Jordan Endowed Professorship in Sociology at the University of Washington. I thank Maria Grigoryeva for her helpful comments and editorial suggestions on earlier drafts.

2. Jaeger and Selznick's (1964: 657) concept of culture has been criticized for embracing an absolute, not relative, concept of culture in which contemporary "cultured man" in Western society is viewed as culturally superior.

3. I would argue that, as with Kornhauser's (1978) work, Parsons's (1937) contribution is not the particular functionalist theory he proposed, but rather the incisive analytic categories he used to outline the requisites for a social theory.

4. This practice parallels Parsons's (1937) selective emphasis in his characterization of theories of Durkheim, Pareto, and Weber, leading to his famous conclusion that each had independently converged on a voluntaristic theory of social action to which Parsons subscribed - a conclusion rejected by most social theorists (e.g., Warner 1978; Levine 1980).

5. This seemed particularly fitting as a tribute to Cressey's memory because, after publishing my MA thesis on testing control theory and differential association (see Matsueda 1982), Don had encouraged me to write an essay on the current status of differential association theory (Matsueda 1988). Later, Travis Hirschi's student, Barbara Costello (1997) tried to defend Kornhauser from my critique, to which I responded (Matsueda 1997).

6. I initially became aware of Kornhauser (1978) through Travis Hirschi. I sent him a copy of my MA thesis, thanking him for helping me access the Richmond data. He suggested I had gotten control theory right, but he questioned my interpretation of Sutherland, and recommended Kornhauser (1978). Upon reading the book, I was impressed at the level of scholarship, the treatment of theoretical assumptions, and the use of causal models, but was horrified by her treatment of Sutherland. 
7. Under criminal law, the justifiable defense of necessity suggests that, under some circumstances, the greater harm should be avoided.

8. Kornhauser (1978) was influenced by Phillip Selznick, and in particular, Jaeger and Selznick's (1964) extension of Parsons to a "normative theory of culture." In emphasizing the treatment of conventional culture as a variable, Jaeger and Selznick note in passing that delinquency is not due to differential association but to something more "pathological." Later, in his book on community, morality, and modernism, Selznick (1992) — despite being influenced by Dewey and Mead - embraces Kornhauser's (1978) critique of Sutherland in discussing the control of delinquency.

9. Sutherland (1947) also gave an explicit scope condition on differential association theory: it is a theory of the criminal violation of laws, and not a theory of deviance or antisocial behavior (see Cressey 1960).

10. At times, Kornhauser (1978) interprets Sutherland's examples as literal generalizations. For example, Akers (1996) shows how Kornhauser interprets Sutherland's example of Indian tribal culture, in which religious norms prescribe certain forms of violence to outsiders, but the legal norms proscribe all violence, to be a literal representation of Sutherland's theory.

11. Kornhauser (1978) here is not helpful, perhaps because she was influenced so strongly by Parsons, who lacked a theory of cognition (see Warner 1978), Kornhauser does not discuss a cognitive theory apart from a rudimentary weighing of costs and benefits.

12. I am excluding much of what falls under the rubric of "the cultural turn" in sociology, including cultural studies and post-modern approaches to culture that eschew causal explanation in favor of deconstruction, textual analysis, and thick description. For a treatment of such approaches in criminology, see Ferrell (1999).

13. Note that this is a fundamental shift in objective from taking a phenomenological approach to understand how actors accomplish a sense of order to a social scientific approach to identify causal explanation of the outcome of interaction.

14. Individuals select into situations, but once selected, the situation in part constitutes action. This formulation brings situations to the forefront of purposive action. With respect to crime, then, opportunity theories, routine activities, and situational explanations play a crucial role (e.g., Cohen and Felson 1979; Wilcox et al. 2003).

\section{References}

Akers, Ronald L. 1996. "Is Differential Association/Social Learning Cultural Deviance Theory?" Criminology 34: 229-247.

Alexander, Jeffrey C. 1983. Theoretical Logic in Sociology, Vol. 4: The Modern Reconstruction of Classical Thought-Talcott Parsons. Berkeley: University of California Press.

- 1990. "Analytic Debates: Understanding the Relative Autonomy of Culture." Pp. 1-27 in Jeffrey C. Alexander and Steven Seidman (eds.), Culture and Society: Contemporary Debates. Cambridge, UK: Cambridge University Press.

Anderson, Elijah. 1999. Code of the Street: Decency, Violence and the Moral Life of the Inner City. New York: W. W. Norton.

Bateson, Gregory. 1972. Ecology of Mind: Collected Essays in Anthropology, Psychiatry, Evolution, and Epistemology. Northvale, NJ: Jason Aronson.

Bourgois, Philippe. 2003. In Search of Respect: Selling Crack in El Barrio. Cambridge, UK: Cambridge University Press.

Bursik, Robert J., Jr., and Jim Webb. 1982. "Community Change and Patterns of Delinquency." American Journal of Sociology 88: 24-42.

Camic, Charles. 1987. "The Making of a Method: A Historical Reinterpretation of the Early Parsons.” American Sociological Review 52: 421-439. 
1989. "Structure after 50 Years: Anatomy of a Charter." American Journal of Sociology 95: 38-107.

Clinard, Marshall B., and Peter C. Yeager. 1980. Corporate Crime. New York: Free Press.

Cloward, Richard A., and Lloyd E. Ohlin. 1960. Delinquency and Opportunity: A Theory of Juvenile Gangs. New York: Free Press.

Cohen, Albert K. 1955. Delinquent Boys: The Subculture of the Gang. Glencoe, IL: Free Press.

Cohen, Lawrence E., and Marcus Felson. 1979. "Social Change and Crime Rate Trends: A Routine Activity Approach.” American Sociological Review 44: 588-608.

Coleman, James S. 1990. Foundations of Social Theory. Cambridge, MA: Harvard University Press.

Costello, Barbara J. 1997. "On the Logical Adequacy of Cultural Deviance Theories." Theoretical Criminology 1: 403-28.

Cressey, Donald R. 1960. "Epidemiology and Individual Conduct: A Case from Criminology." The Pacific Sociological Review 3: 47-58.

-1969. Theft of the Nation. New York: Harper and Row.

. [1953] 1973. Other People's Money: A Study of the Social Psychology of Embezzlement. Glencoe, IL: Free Press.

Dewey, John. 1922. Human Nature and Conduct. New York: The Modern Library. .1958. Experience and Nature. New York: Dover.

Emirbayer, Mustafa, and Ann Mische. 1998. "What Is Agency?" American Journal of Sociology 103: 962-1023.

Ferrell, Jeff. 1999. "Cultural Criminology.” Annual Review of Sociology 25: 395-418.

Giordano, Peggy C., Stephen A. Cernkovich, and Jennifer L. Rudolph. 2002. "Gender, Crime, and Desistance: Toward a Theory of Cognitive Transformation." American Journal of Sociology 107: 990-1064.

Glaser, Barney G., and Anselm L. Strauss. 1964. "Awareness Contexts and Social Interaction." American Sociological Review 29: 669-679.

Goffman, Erving. 1974. Frame Analysis: An Essay on the Organization of Experience. Cambridge, MA: Harvard University Press.

Gottfredson, Michael R., and Travis Hirschi. 1990. A General Theory of Crime. Stanford, CA: Stanford University Press.

Gross, Neil. 2009. “A Pragmatist Theory of Social Mechanisms.” American Sociological Review 74: 358-379.

Hagan, John, and Wenona Rymond-Richmond. 2009. Darfur and the Crime of Genocide. Cambridge, UK: Cambridge University Press.

Hannerz, Ulf. 1969. Soulside: Inquiries into Ghetto Culture and Community. New York: Columbia University Press.

Heitgard, Janet L., and Robert J. Bursik, Jr. 1987. "Extracommunity Dynamics and the Ecology of Delinquency." American Journal of Sociology 92: 775-787.

Hirschi, Travis. 1969. Causes of Delinquency. Berkeley: University of California Press. 1996. "Theory without Ideas: Reply to Akers." Criminology 34: 249-256.

Horowitz, Ruth. 1983. Honor and the American Dream: Culture and Identity in a Chicano Community. New Brunswick, NJ: Rutgers University Press.

Jaeger, Gertrude, and Phillip Selznick. 1964. "A Normative Theory of Culture.” American Sociological Review 29: 633-669.

Jankowski, Martin Sanchez. 1991. Islands in the Street: Gangs and American Urban Society. Berkeley: University of California Press.

Joas, Hans. 1993. Pragmatism and Social Theory. Translated by Jeremy Gaines, Raymond Meyer, and Steven Minner. Chicago: University of Chicago Press. 1996. The Creativity of Action. Chicago: University of Chicago Press. 
Katz, Jack. 1988. Seductions of Crime: Moral and Sensual Attractions in Doing Evil. New York: Basic Books.

Kornhauser, Ruth Rosner. 1978. Social Sources of Delinquency: An Appraisal of Analytic Models. Chicago: University of Chicago Press.

- 1984. Social Sources of Delinquency: An Appraisal of Analytic Models, paperback ed. Chicago: University of Chicago Press.

Kroeber, A. L., and Talcott Parsons. 1958. "The Concepts of Culture and of Social System." American Sociological Review 23: 582-583.

Kubrin, Charis E., and Ronald Weitzer. 2003. "New Directions in Social Disorganization Theory." Journal of Research in Crime and Delinquency 40: 374-402.

Lamont, Michèle, and Mario Luis Small. 2008. "How Culture Matters: Enriching Our Understanding of Poverty." Pp. 76-102 in Ann Chih Lin and David R. Harris (eds.), The Colors of Poverty: Why Racial and Ethnic Disparities Persist. New York: Russell Sage.

Lareau, Annette. 2002. "Invisible Inequality: Social Class and Childrearing in Black Families and White Families." American Sociological Review 67: 747-776.

Laub, John H., and Robert J. Sampson. 2003. Shared Beginnings, Divergent Lives: Delinquent Boys at Age 70. Cambridge, MA: Harvard University Press.

Levine, Donald N. 1980. "Introduction." Pp. ix-lxv in Donald N. Levine (ed.), George Simmel on Individuality and Social Forms. Chicago: University of Chicago Press.

Lewis, Oscar. 1966. "The Culture of Poverty." Scientific American 215: 19-25.

Lieberson, Stanley. 1991. "Small N's and Big Conclusions: An Examination of the Reasoning in Comparative Studies Based on a Small Number of Cases." Social Forces 70: 307-320.

Matsueda, Ross L. 1982. "Testing Control Theory and Differential Association: A Causal Modeling Approach." American Sociological Review 47: 489-504.

1988. "The Current State of Differential Association Theory." Crime and Delinquency 34: 277-306.

- 1997. "Cultural Deviance Theory: The Remarkable Persistence of a Flawed Term." Theoretical Criminology 1: 429-452.

- 2006a. "Differential Social Organization, Collective Action, and Crime." Crime, Law and Social Change 46: 3-33.

. 2006b. "Criminological Implications of the Thought of George Herbert Mead." Pp. 77-108 in Mathieu Deflem (ed.)., Sociological Theory and Criminological Research: Views from Europe and the United States. Oxford, UK: Elsevier Science.

- 2008. "On the Compatibility of Social Disorganization and Self Control." Pp. 102-126 in Erich Goode (ed.), Out of Control: Assessing the General Theory of Crime. Stanford, CA: Stanford University Press.

- 2013. "Rational Choice Research in Criminology: A Multi-Level Framework." Pp. 283-321 in Raphael Wittick, Tom Snijders, and Victor Nee (eds.), Handbook of Rational Choice Social Research. Palo Alto, CA: Stanford University Press.

Matza, David. 1964. Delinquency and Drift. New York: Wiley.

Mead, George Herbert. 1934. Mind, Self, and Society. Chicago: University of Chicago Press.

Merton, Robert K. 1938. "Social Structure and Anomie." American Sociological Review 3: $672-682$.

. 1968. Social Theory and Social Structure. Enlarged ed. New York: Free Press.

Miller, Walter B. 1958. "Lower Class Culture as a Generating Milieu of Gang Delinquency." Journal of Social Issues 14: 5-19.

Mills, C. Wright. 1940. "Situated Action and Vocabulary of Motive." American Sociological Review 5: 904-913. 
1943. "The Professional Ideology of Social Pathologists." American Journal of Sociology 49: 165-180.

Moynihan, Daniel P. 1965. The Negro Family: The Case for National Action. Washington, DC: Office of Policy Planning and Research, U.S. Department of Labor.

Parsons, Talcott. 1937. The Structure of Social Action. New York: Free Press. 1951. The Social System. New York: Free Press.

Reiss, Albert J., Jr. 1951. "Delinquency as the Failure of Personal and Social Controls." American Sociological Review 16: 196-207.

Sampson, Robert J. 2012. Great American City: Chicago and the Enduring Neighborhood Effect. Chicago: University of Chicago Press.

Sampson, Robert J., and Dawn Jeglum Bartusch. 1998. "Legal Cynicism and (Subcultural) Tolerance of Deviance: The Neighborhood Context of Racial Difference." Law and Society Review 32: 777-804.

Sampson, Robert J., and Lydia Bean. 2006. "Cultural Mechanisms and Killing Fields: A Revised Theory of Community-Level Racial Inequality.” Pp. 8-38 in Ruth D. Peterson, Lauren J. Krivo, and John Hagan (eds.), The Many Colors of Crime: Inequalities of Race, Ethnicity, and Crime in America. New York: New York University Press.

Sampson, Robert J., and Corina Graif. 2009. "Neighborhood Social Capital as Differential Social Organization Resident and Leadership Dimensions." American Behavioral Scientist 52: 1579-1605.

Sampson, Robert J., and W. Byron Groves. 1989. "Community Structure and Crime: Testing Social-Disorganization Theory.” American Journal of Sociology 94: 774-802.

Sampson, Robert J., and John H. Laub. 1993. Crime in the Making: Pathways and Turning Points through Life. Cambridge, MA: Harvard University Press.

Sampson, Robert J., Jeffrey D. Morenoff, and Felton Earls. 1999. "Beyond Social Capital: Spatial Dynamics of Collective Efficacy for Children." American Sociological Review 64: 633-660.

Sampson, Robert J., and William Julius Wilson. 1995. "Toward a Theory of Race, Crime, and Urban Inequality." Pp. 37-54 in John Hagan and Ruth D. Peterson (eds.) Crime and Inequality. Stanford, CA: Stanford University Press.

Schutz, Alfred. [1932] 1967. The Phenomenology of the Social World. Translated by George Walsh and Frederick Lehnert. Evanston, IL: Northwestern University Press.

Sellin, Thorsten. 1938. "Culture Conflict and Crime." American Journal of Sociology 44: 97-103.

Selznick, Philip. 1992. The Moral Commonwealth: Social Theory and the Promise of Community. Berkeley: University of California Press.

Shaw, Clifford R. 1930. The Jack-Roller: A Delinquent Boy's Own Story. Chicago: University of Chicago Press.

Shaw, Clifford R., and Henry D. McKay. [1942] 1969. Juvenile Delinquency and Urban Areas, revised ed. Chicago: University of Chicago Press.

Short, James F., Jr., and Fred L. Strodtbeck. 1965. Group Process and Gang Delinquency. Chicago: University of Chicago Press.

Simpson, Sally S. 2002. Corporate Crime, Law, and Social Control. Cambridge, UK: Cambridge University Press.

Small, Mario L. 2002. "Culture, Cohorts, and Social Organization Theory: Understanding Local Participation in a Latino Housing Project." American Journal of Sociology 108: 1-54.

Small, Mario Luis, David J. Harding, and Michele Lamont. 2010. "Reconsidering Culture and Poverty." Annals of the American Academy of Political and Social Science 629: 6-26. 
Snow, David A., E. Burke Rochford, Jr., Steven K. Worden, and Robert D. Benford. 1986. "Frame Alignment Processes, Micromobilization, and Movement Participation." American Sociological Review 51: 464-481.

Somers, Margaret R. 1995. "What's Political or Cultural about Political Culture and the Public Sphere? Toward an Historical Sociology of Concept Formation." Sociological Theory 13: 113-144.

Sutherland, Edwin H. 1926. "The Biological and Sociological Processes." Papers and Proceedings of the Twentieth Annual Meeting of the American Sociological Society 20: $58-65$.

- [1942] 1973. "Development of the Theory." Pp. 13-20 in Karl Schuessler (ed.), Edwin H. Sutherland on Analyzing Crime. Chicago: University of Chicago Press.

—. [1943] 1973. "Wartime Crime." Pp. 120-130 in Karl Schuessler (ed.), Edwin H. Sutherland on Analyzing Crime. Chicago: University of Chicago Press.

_. [1944] 1973. "Critique of the Theory." Pp. 30-41 in Karl Schuessler (ed.), Edwin H. Sutherland on Analyzing Crime. Chicago: University of Chicago Press.

. 1947. Principles of Criminology. 4th ed. Philadelphia: J. B. Lippincott.

Swidler, Ann. 1986. "Culture in Action: Symbols and Strategies." American Sociological Review 51: 273-286.

Sykes, Gresham M., and David Matza. 1957. "Techniques of Neutralization: A Theory of Delinquency." American Sociological Review 22: 664-70.

Thomas, William I. 1923. The Unadjusted Girl. Boston: Little, Brown.

Thomas, William I., and Dorothy Swaine Thomas. 1928. The Child in America: Behavior Problems and Programs. New York: Alfred A. Knopf.

Thrasher, Frederic M. 1927. The Gang: A Study of 1,313 Gangs in Chicago. Chicago: University of Chicago Press.

Toby, Jackson. 1957. "Social Disorganization and Stake in Conformity: Complementary Factors in the Predatory Behavior of Hoodlums." Journal of Criminal Law, Criminology and Police Science 48: 12-17.

Warner, Stephen R. 1978. "Toward a Reformulation of Action Theory: Paying the Cognitive Element Its Due.” American Journal of Sociology 83: 1317-1349.

Wikström, Per-Olof H., Dietrich Oberwittler, Kyle Treiber, and Beth Hardie. 2013. Breaking Rules: The Social and Situational Dynamics of Young People's Urban Crime. Oxford, UK: Oxford University Press.

Wilcox, Pamela, Kenneth C. Land, and Scott A. Hunt. 2003. Criminal Circumstance: A Dynamic Multicontextual Criminal Opportunity Theory. New York: Aldine de Gruyter.

Wilson, William Julius. 1987. The Truly Disadvantaged: The Inner City, the Underclass, and Public Policy. Chicago: University of Chicago Press.

- 2010. "Why Both Social Structure and Culture Matter in a Holistic Analysis of Inner-City Poverty." Annals of the American Academy of Political and Social Science 629: 200-219.

Wirth, Louis. 1931. "Culture Conflict and Misconduct." Social Forces 9: 484-492.

Wolfgang, Marvin E., and Franco Ferracuti. 1967. The Subculture of Violence: Towards an Integrated Theory in Criminology. Beverly Hills, CA: Sage. 
